\section{Cadmium the missing link between smoking and increased rheumatoid disease activity?}

Ospelt et $a l^{1}$ have observed a number of important and interesting observations in their paper "Smoking induces transcription of the heat shock protein system in the joints". It was observed that when synovial fibroblasts were incubated with 5\% cigarette smoke extract there was a significant upregulation of the heat shock proteins DnaJA4, DnaJB4, DnaJC6, HspB8 and Hsp70. This important scientific work follows on from the overwhelming epidemiological evidence that smoking is associated with rheumatoid arthritis (RA). A meta-analysis of seven case control and three prospective cohort studies demonstrated a doubling of risk of developing RA (RR 2.07 95\% CI 1.15 to 3.73) when comparing those with the highest cumulative exposure versus those with the lowest. ${ }^{2}$

Ospelt et al correctly comment in their paper that cigarette smoke contains potentially hundreds of chemicals that may have a deleterious effect on health. We propose that one such hazardous component of cigarette smoke is cadmium and could account for the observations made by Ospelt et al. The mean whole blood cadmium concentration in smokers is reported as double that of in non-smokers $(2.67 \pm 1.21 \mu \mathrm{g} / \mathrm{L}$ vs 1.37 $\pm 0.45 \mu \mathrm{g} / \mathrm{L}){ }^{3}$ Diet is the main source of cadmium exposure in non-smokers. ${ }^{4}$ Intestinal absorption is increased in those with iron deficiency and higher levels of cadmium are found in women of childbearing age than age-matched men. ${ }^{5}$

Increased cadmium exposure has been observed in men with RA irrespective of smoking history ${ }^{6}$ and is observed in the synovial fluid of patients with RA. ${ }^{7}$ Cadmium inhalation has been linked to the development of chronic obstructive pulmonary disease (COPD). ${ }^{8}$ COPD has a number of striking similarities to RA. COPD and RA are associated with cigarette smoking, upregulation of interleukin (IL)-8 and subsequent neutrophil and macrophage infiltration, activation of matrix metalloproteinases and increased fibroblast activation (reviewed in ${ }^{9}$ ).

A study of the effects of low cadmium concentrations in HepG2 cells demonstrated an upregulation of Hsp70 and IL- ${ }^{10} 11$ and it is noteworthy that cigarette smoke extract upregulates IL-8 production by synovial fibroblasts. ${ }^{12}$

It would be interesting to know if the observations made by Ospelt could be reproduced with a solution of cadmium sulfate at a concentration commensurate with the concentration of cadmium observed in the synovial fluid of long-standing smokers with RA. Additionally a cadmium chelating agent could be added to the cigarette condensate used by Ospelt et al to determine if their important observations can still be observed independent of cadmium.

\section{Matthew Cates, David Hutchinson}

Treliske Hospital, Cornwall, UK

Correspondence to Dr David Hutchinson, Royal Cornwall Hospital, Rheumatology Department, Truro, Cornwall, UK; david.hutchinson@rcht.cornwall.nhs.uk

Competing interests None.

Provenance and peer review Not commissioned; internally peer reviewed.

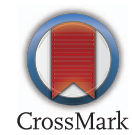

To cite Cates M, Hutchinson D. Ann Rheum Dis 2015;74:e1.

Received 26 August 2014

Accepted 6 September 2014

Published Online First 23 September 2014

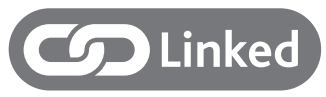

- http://dx.doi.org/10.1136/annrheumdis-2014-206590

Ann Rheum Dis 2015;74:e1. doi:10.1136/annrheumdis-2014-206538

\section{REFERENCES}

1 Ospelt C, Camici GG, Engler A, et al. Smoking induces transcription of the heat shock protein system in the joints. Ann Rheum Dis 2014;73:1423-6.

2 Di Giuseppe D, Discacciati A, Orsini N, et al. Cigarette smoking and risk of rheumatoid arthritis: a dose-response meta-analysis. Arthritis Res Ther 2014;16:R61.

3 Bernhard D, Rossmann A, Wick G. Metals in cigarette smoke. IUBMB Life 2005;57:805-9.

4 Ferrari $P$, Arcella $D$, Heraud $F$, et al. Impact of refining the assessment of dietary exposure to cadmium in the European adult population. Food Addit Contam Part A Chem Anal Control Expo Risk Assess 2013;30:687-97.

5 Lee B-K, Kim Y. Sex-specific Profiles of Blood Metal Levels Associated with Metal? Iron Interactions. Safety and Health at Work. 2014. doi:10.1016/j.shaw.2014.06.005

6 Afridi $\mathrm{HI}$, Kazi TG, Brabazon D, et al. Association between essential trace and toxic elements in scalp hair samples of smokers rheumatoid arthritis subjects. Sci Total Environ 2011:412-413:93-100.

7 Pedersen LM, Christensen JM. Chromium, nickel and cadmium in biological fluids in patients with rheumatoid arthritis compared to healthy controls. Acta Pharmacol Toxicol (Copenh) 1986;59(Suppl 7):392-5.

8 Kirschvink N, Vincke G, Fievez L, et al. Repeated cadmium nebulizations induce pulmonary MMP-2 and MMP-9 production and emphysema in rats. Toxicology 2005;211:36-48.

9 Perry E, Kelly C, Eggleton P, et al. The lung in ACPA-positive rheumatoid arthritis: an initiating site of injury? Rheumatology (Oxford) 2014.

10 Souza V, Escobar Md Mdel C, Gomez-Quiroz L, et al. Acute cadmium exposure enhances AP-1 DNA binding and induces cytokines expression and heat shock protein 70 in HepG2 cells. Toxicology 2004;197:213-28.

11 Cormet-Boyaka E, Jolivette K, Bonnegarde-Bernard A, et al. An NF-kappaB-independent and Erk1/2-dependent mechanism controls CXCL8/L-8 responses of airway epithelial cells to cadmium. Toxicol Sci 2012;125:418-29.

12 Engler A, Niederer F, Klein K, et al. SIRT6 regulates the cigarette smoke-induced signalling in rheumatoid arthritis synovial fibroblasts. J Mol Med (Berl) 2014;92:757-67. 